\title{
How feasible is it to conform to the European guidelines on administration of activated charcoal within one hour of an overdose?
}

\author{
A Karim, S Ivatts, P Dargan, A Jones
}

\begin{abstract}
Objectives-The European and American position statement on the use of activated charcoal recommends its administration within an hour of ingestion of a charcoal binding poison. But in reality, this time limit is difficult to follow for the majority of poisoned patients. This study aimed to examine the treatment of acutely poisoned patients with activated charcoal in an accident and emergency (A\&E) department.

Methods-63 patients who had taken potentially serious overdoses and required hospital admission from a London teaching hospital A\&E department were identified over a six month period. The patients' case notes were analysed for age, sex, substances taken, and the timing of their management within the $A \& E$ department. Results-Median time of arrival after overdose was 136 minutes, and only 15 patients presented within an hour. Ten of these 15 patients were given activated charcoal, and only four of the 10 received it within the one hour limit. Sixteen patients received charcoal outside the time limit. Subanalysis of the individual cases given charcoal shows that triaging is fast (median five minutes), but a significant time delay occurs after this before charcoal is administered (median 21 minutes).

Conclusions-These results are likely to be exaggerated in rural hospitals and demonstrate the difficulty of adhering to the recommended guidelines, unless activated charcoal can be safely administered to appropriate patients in the prehospital environment.

(Emerg Med f 2001;18:390-392)
\end{abstract}

Keywords: overdose; poisoning; activated charcoal

The treatment of acute poisoning remains an important part of the workload of any accident and emergency (A\&E) department in the UK. The three most widely used gastric decontamination procedures are gastric lavage,${ }^{1}$ whole bowel irrigation $^{2}$ and activated charcoal, ${ }^{3}$ and of these three, activated charcoal is now the treatment of choice for most poisons, because gastric lavage and whole bowel irrigation tend to be more used for serious overdoses of substances not adsorbed by charcoal. Ipecacuanha (ipecac) induced emesis is no longer recommended because it is ineffective at removing significant quantities of poisons from the stomach and the vomiting it produces can confuse the clinical picture and prevents the use of activated charcoal. ${ }^{4}$

The role of activated charcoal in the treatment of poisoning has recently been reviewed in a position statement from the European Association of Poisons Centres and American Academy of Clinical Toxicology. ${ }^{3}$ Activated charcoal is highly effective at adsorbing most poisons because of its large surface area and porous structure and its use is advocated in all patients who present within one hour of ingestion of a potentially toxic amount of poison that binds to charcoal. Activated charcoal can be given through a nasogastric tube to those who feel they cannot swallow activated charcoal or if patients have a reduced level of consciousness. The airway must be adequately protected before activated charcoal is given to any patient.

The aim of this study was to investigate what proportion of patients who presented with potentially serious poisoning to a London teaching hospital A\&E department over a six month period were given activated charcoal and how many of those received it within the recommended 60 minutes after overdose. The study also examined how many patients who should have received charcoal did not do so, and performed a time analysis of the movement of poisoned patients within the $A \& E$ department. The A\&E department involved in this study gave permission for retrospective analysis of their records to be undertaken but we have not named the department in this publication for reasons of confidentiality.

\section{Methods}

Altogether 190 patients coded as "overdose" and requiring hospital admission were identified from the computerised $A \& E$ database at a London teaching hospital over a six month period. Criteria for exclusion from the study
Accepted for publication 15 March 2001 
Table 1 Substances taken in overdose

\begin{tabular}{ll}
\hline Substance & Patients $(n)$ \\
\hline Paracetamol & 37 \\
Salicylates & 7 \\
Carbamazepine & 4 \\
Dihydrocodeine & 4 \\
Ibuprofen & 3 \\
Benzodiazepines & 3 \\
Trifluoperazine & 2 \\
Propranolol & 2 \\
Ferrous sulphate & 1 \\
\hline
\end{tabular}

comprised a clinically insignificant overdose, an intravenous route of administration, and presentation more than 24 hours after ingestion of an overdose. Sixty three patients were identified after exclusions, and their case notes were analysed for the following information:

- Age

- Sex

- Substance(s) taken (see table 1)

- Time of poisoning

- Time of arrival in A\&E

- Time of triage

- Time seen by doctor

- Timing of activated charcoal if this was administered

\section{Results}

Of the 63 patients, 30 were male and 33 female and the age range was between 15 and 60 years

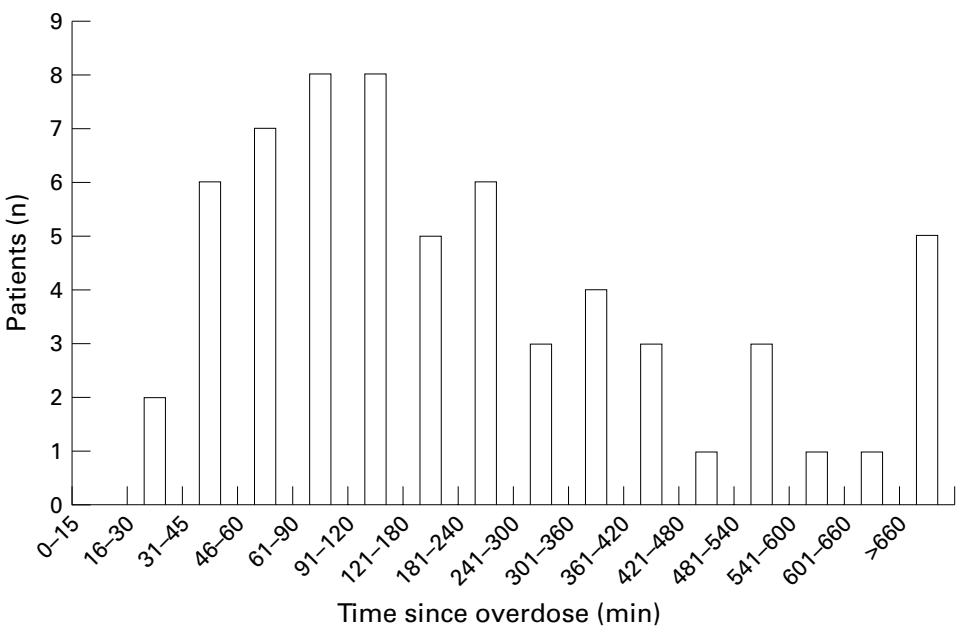

Figure 1 Distribution of times of presentation after overdose $(n=63)$.

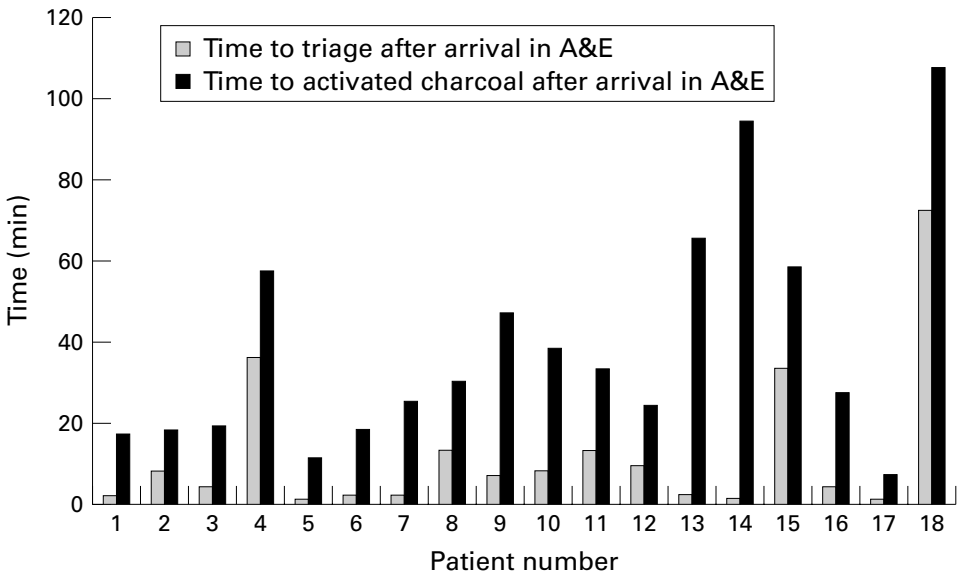

Figure 2 Delay in triage and delay in administration of charcoal, from the time of arrival in $A \mathcal{E} E$ ( $n=18$ patients). (median age 30). There was a wide range of intervals between the time of poisoning and presentation to the $\mathrm{A} \& \mathrm{E}$ department, varying from 21 minutes up to 16 hours (median 136 minutes), as shown in figure 1 .

Only 15 of 63 patients identified with a potentially serious overdose presented to $A \& E$ within one hour (fig 1) of whom 10 were given charcoal and five were not. However, after adding on time to triage the patients and then administer the charcoal, only 4 of the 10 patients given charcoal actually received it within one hour of taking their overdose.

Analysis of all 63 cases showed that a total of 20 patients had been given charcoal, even though only 10 had presented within one hour. Further time analysis of 18 of the patients given activated charcoal is shown in figure 2 , comparing time taken to triage the poisoned patient with time taken to actually administer the charcoal. Time taken to administer the charcoal after triaging varied from 6 minutes to 93 minutes (median 21 minutes).

\section{Discussion}

This study shows the difficulty of conforming to the European guidelines on the use of activated charcoal within one hour of an overdose in acute poisoning. There are, of course, difficulties in obtaining an accurate history of timing of ingestion from poisoned patients but because the majority of poisoned patients presented outside the time window, this made them ineligible for treatment. For the significant number who did present within one hour of taking their overdose, delays within the $\mathrm{A} \& \mathrm{E}$ department led to the majority of this group receiving their charcoal late. It is important that those who have ingested a potentially serious overdose and have presented within the one hour interval are rapidly identified and fast tracked for activated charcoal treatment. This decision needs to be taken by the triage staff, as they have initial access to the patient. There is a significant delay to see a doctor after triaging, and this is far greater than the time taken for triaging after patient arrival.

However, the needs of poisoned patients have to be taken in the context of the needs of other patient groups attending the $A \& E$ department. It would, in our view for example, be inappropriate to strive to achieve charcoal administration within one hour, where improved outcome is not supported by randomised controlled clinical trials ${ }^{1-3}$ at the expense of adequate early assessment of patients with possible myocardial infarction. However, it is possible that the A\&E department may not be the optimal place to administer the charcoal, and it could be given in a prehospital setting.

The difficulties of achieving charcoal administration within one hour in the hospital environment are likely to be exaggerated in more remote rural areas around the country, where delays in accessing and transporting patients to A\&E departments and poorer staffing numbers within those departments will serve to further reduce the number of poisoned patients who are able to have activated charcoal 
treatment within the recommended time limit. It is equally important, however, that patients who present too late for activated charcoal to have efficacy do not receive it and this study showed a significant number of patients received activated charcoal when they should not have done so. This is concerning as the administration of charcoal is not entirely risk free and has been associated with aspiration pneumonitis ${ }^{5}$ or charcoal bezoars. ${ }^{6}$ This is particularly the case where multiple doses of charcoal have been recommended, for example for the treatment of poisoning with theophylline and anticonvulsants. Only in four of the patients above (those who had taken carbamazepine) would delayed administration of charcoal be expected to be of any value, and then only if repeated doses were administered. ${ }^{7}$

Pilot studies strongly suggest that prehospital administration of activated charcoal by paramedics in the majority of poisoned patients, who are conscious with an intact gag reflex, results in the earliest possible administration of charcoal and this may be one aspect of the future of emergency treatment of poisoned patients. ${ }^{8-10}$

It is timely administration of charcoal where it is appropriate in the prehospital and hospital environment that will remain a challenge. Currently it is very difficult to conform to the new European and American guidelines and to do so will require a change in the prioritisation and initial treatment of poisoned patients.

Funding: none.

Conflicts of interest: none.

1 American Academy of Clinical Toxicology; European Association of Poison Control Centres and Clinical Toxicologists. Position statement: Gastric lavage. Clin Tox 1997;35:711-19.

2 American Academy of Clinical Toxicology; European Association of Poison Control Centres and Clinical Toxicologists. Position statement: Whole bowel irrigation. Clin Tox 1997;35:753-62.

3 American Academy of Clinical Toxicology; European Association of Poison Control Centres and Clinical Toxicologists. Position statement: Activated charcoal. Clin Tox 1997;35: 721-741.

4 American Academy of Clinical Toxicology; European Association of Poison Control Centres and Clinical Toxicologists.
Position statement: Ipecacuanha. Clin Tox 1997;35:699-709.

5 Menzies DG, Busutill A, Prescott LE. Fatal pulmonary aspiMenzies DG, Busutil A, Prescott LE. Fatal pulmonary a
ration of oral activated charcoal. BMF 1988;297:459-60.

6 Ray MJ, Padin DR, Condie JD, et al. Small bowel obstruction secondary to amitriptyline overdose. Dig Dis Sci 1998;33 106-7.

7 Jones AL, Proudfoot AT. Features and management of poisoning with modern drugs used to treat epilepsy. $Q \mathcal{F} M e d$ 1998;91:325-32

8 Crockett R, Krishel SJ, Manoguerra A, et al. F Emerg Med 1996;14:335-8.

9 Allison TB, Gough JF, Brown LH, et al. Prehospital Emergency Care 1997;1:73-5.

10 Jones AL. Initial management of poisoned patients in the outof-hospital environment. Prehospital Emergency Care 1998;2: 